\title{
Photocatalytic Degradation of a Water Soluble Herbicide by Pure and Noble Metal Deposited $\mathrm{TiO}_{2}$ Nanocrystalline Films
}

\author{
Katerina Pelentridou, ${ }^{1}$ Elias Stathatos, ${ }^{2}$ Helen Karasali, ${ }^{3}$ Dionysios D. Dionysiou, ${ }^{4}$ and Panagiotis Lianos ${ }^{1}$ \\ ${ }^{1}$ Engineering Science Department, University of Patras, 26500 Patras, Greece \\ ${ }^{2}$ Electrical Engineering Department, Technological-Educational Institute of Patras, 26334 Patras, Greece \\ ${ }^{3}$ Benaki Phytopathological Institute, Pesticide control and Phytopharmacy, 14561 Athens, Greece \\ ${ }^{4}$ Department of Civil and Environmental Engineering, University of Cincinnati, Cincinnati, OH 45221-0071, USA
}

Correspondence should be addressed to Elias Stathatos, estathatos@teipat.gr

Received 1 April 2008; Revised 12 May 2008; Accepted 5 July 2008

Recommended by Jean-Marie Herrmann

We present the photocatalytic degradation of a water soluble sulfonylurea herbicide: azimsulfuron in the presence of titania nanocrystalline films. Efficient photodegradation of herbicide was achieved by using low-intensity black light tubes emitting in the Near-UV. The degradation of the herbicide follows first-order kinetics according to the Langmuir-Hinshelwood model. Intermediate products were identified by the LC-MS-MS technique during photocatalytic degradation. In order to increase photodegradation rate of the herbicide, we examined the effect of titania modification by depositing noble metals at various quantities and valence states. The presence of platinum at neutral valence state and optimum concentration induced higher photodegradation rates while silver-modified titania exhibited similar photocatalytic rates with those obtained with pure nanocrystalline $\mathrm{TiO}_{2}$ films. Finally, the effect of initial $\mathrm{pH}$ value was also examined. Acidic or alkaline media were unfavorable for azimsulfuron photodegradation.

Copyright (c) 2008 Katerina Pelentridou et al. This is an open access article distributed under the Creative Commons Attribution License, which permits unrestricted use, distribution, and reproduction in any medium, provided the original work is properly cited.

\section{INTRODUCTION}

Photodegradation of various organic pollutants by photocatalysis, using wide bandgap semiconductors, has been extensively studied [1-3]. Among them, $\mathrm{TiO}_{2}$ a relatively inexpensive semiconductor exhibits high photocatalytic activity, stability in aqueous solution, nontoxicity [4, 5], and so forth. However, $\mathrm{TiO}_{2}$ usage has a few drawbacks; for example, it absorbs only in the UVA part of the light spectrum where solar radiation is only $2-3 \%$ of the total reaching the surface of the Earth [6]. Moreover, the application of $\mathrm{TiO}_{2}$ for photocatalytic oxidation of organic molecules is limited by high charge carrier recombination rates that results in low quantum efficiency. In recent years, surface metallization of $\mathrm{TiO}_{2}$ has received considerable attention as an option to overcome the high degree of charge carrier recombination [7-10]. Platinum, and some other noble metals, may be used for this purpose thus providing an electron sink. In addition, they may extent $\mathrm{TiO}_{2}$ absorbance in the Visible [11]. The presence of a metal at the surface of $\mathrm{TiO}_{2}$ results in the formation of a Schottky barrier at the metal-semiconductor interface, which facilitates the interfacial electron transfer and subsequently encourages the charge carrier separation [12].

Among the various organic substances, which are known as water pollutants, herbicides are a major pollution source for both underground and surface waters. Advanced oxidation processes are used, among others, also for the degradation of herbicides $[13,14]$. Azimsulfuron (AZS, see Scheme 1 for chemical structure) belongs to the class of sulfonylurea herbicides, which have a broad spectrum of weed control, low application rate, and low animal toxicity $[15,16]$. Sulfonylurea herbicides, in addition to playing an important role in modern agriculture, are also degradable by heterogeneous photocatalysis, as it has been proven in the past $[17,18]$. In the present work, sol-gel prepared $\mathrm{TiO}_{2}$ films, which were further modified with noble metal ions, were examined for the photodegradation of AZS in water. The effect of various parameters, such as the amount of metal deposits and $\mathrm{pH}$ value of herbicide aqueous solution, were studied in order to evaluate the optimum conditions for the photocatalytic oxidation of AZS. 


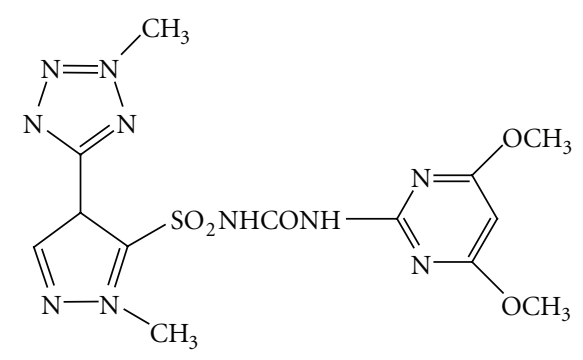

Scheme 1: Chemical structure of AZS.

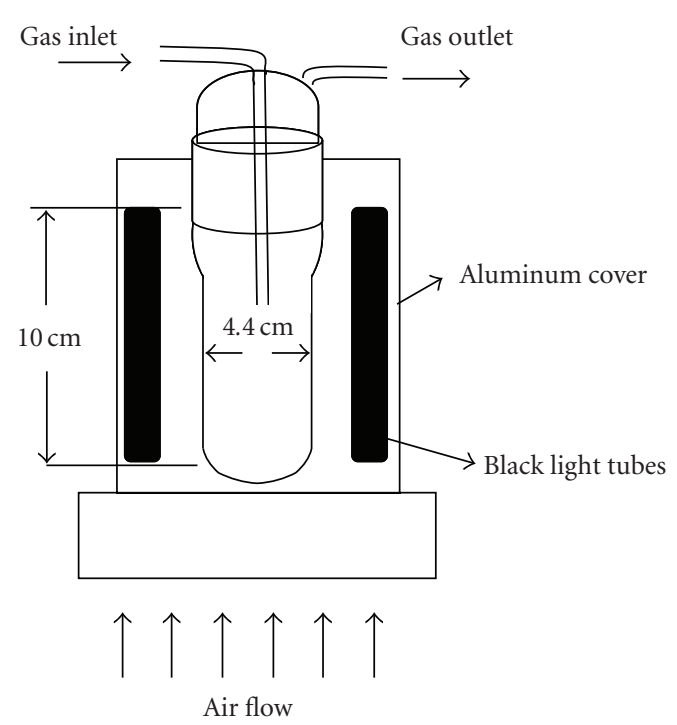

FIgURE 1: Schematic representation of the reactor used in all experiments.

\section{EXPERIMENTAL}

Azimsulfuron, N-[[(4,6-dimethoxy pyrimidin-2-yl)amino] carbonyl]-1-methyl-4-(2-methyl-2H-tetrazole5-yl)-1H-pyrazole-5-sulfonamide (AZS, 99.3\% purity, Scheme 1), was donated by DuPont de Nemours, Puteaux, France. All the rest of reagents were obtained from Sigma-Aldrich, Mo, USA. Millipore water was used in all experiments.

\subsection{Description of the photocatalytic reactor}

The cylindrical reactor schematically shown in Figure 1 was used in all experiments [19]. Air was pumped through the gas inlet using a small pump to ensure continuous oxygen supply to the reaction solution while simultaneously agitating it. In cases where experiments were carried out in the absence of oxygen, the solution was deoxygenated by nitrogen flow and the openings were sealed. Four black light fluorescent tubes of $4 \mathrm{~W}$ nominal power were placed around the reactor. The whole construction was covered with a cylindrical aluminum reflector. Cooling was achieved by air flow from below the reactor using a ventilator. The catalyst was in the form of four-glass rings, covered on both sides with nanocrystalline $\mathrm{TiO}_{2}$ film. Film deposition is described below. The glass rings were of $38 \mathrm{~mm}$ of diameter and $15 \mathrm{~mm}$ height, stacked and coaxially placed inside the reactor. Thus, the total surface of the photocatalyst film was approximately $2 \times 71.6=143 \mathrm{~cm}^{2}$. The intensity of radiation reaching the surface of the film on the side facing lamps was measured with an Oriel radiant power meter and found equal to $0.79 \mathrm{~mW} / \mathrm{cm}^{2}$.

\subsection{Nanocrystalline Titania films and metal deposition}

Titania films were deposited by following the previously reported procedure [20, 21]. Briefly, for $25 \mathrm{~mL}$ solution, $3.6 \mathrm{~g}$ of the nonionic surfactant Triton X-100 (polyoxyethylene10 -isooctylphenyl ether) was mixed with $20 \mathrm{~mL}$ of ethanol, followed by addition of $1.6 \mathrm{~mL}$ of glacial acetic acid and $1.8 \mathrm{~mL}$ of titanium isopropoxide under vigorous stirring. Self organization of the surfactant in this original sol creates organized assemblies that act as templates defining nanoparticle size. The surfactant is burned out during calcination. After a few minutes stirring, the glass rings described above, which were previously thoroughly washed, sonicated in ethanol and dried in a $\mathrm{N}_{2}$ stream, were dipped in the above sol and withdrawn slowly by hand. After the film was dried in air for a few minutes, it was calcined in an oven. The temperature was increased in a ramp rate of $20^{\circ} \mathrm{C} / \mathrm{min}$ up to $550^{\circ} \mathrm{C}$ and left at that temperature for about 10 minutes. When the titania-covered rings were taken out of the oven, they were transparent and optically uniform. The above procedure was repeated several times in order to reach the quantity of catalyst necessary for the purposes of the present work. The final mass of titania on the four glass rings was $80 \mathrm{mg}$ ( $20 \mathrm{mg}$ on each glass ring). Noble metal ions were deposited on titania films by adsorption from aqueous solutions containing one of the following metal salts: $\mathrm{Na}_{2} \mathrm{PtCl}_{4} \cdot x \mathrm{H}_{2} \mathrm{O}$ or $\mathrm{AgNO}_{3}$ at various concentrations (from $10^{-4}$ to $10^{-3} \mathrm{M}$ for the platinum salt and from $5 \times 10^{-4}$ to $10^{-2} \mathrm{M}$ for the silver salt). After the last layer of $\mathrm{TiO}_{2}$ was deposited and immediately after the film was taken out from the oven, the rings were submerged in the salt aqueous solution and were left for half an hour in the dark. Then, the rings were washed, dried, and subjected to UV radiation for 30 minutes; or they were additionally heated at $500^{\circ} \mathrm{C}$ for 15 minutes. UV and heat treatment were performed to reduce cationic species to neutral metallic particles.

\subsection{Photodegradation procedure}

The reactor was filled with $100 \mathrm{~mL}$ water in which $6 \mathrm{mg}$ of AZS were dissolved. Standard solutions were employed in all experiments. AZS is not adsorbed on titania films, however, about an hour of equilibrium was allowed before illumination. The concentration of AZS in solution was monitored by absorption spectrophotometry at $240 \mathrm{~nm}$ using quartz cuvettes. In order to assure linear relationship between absorbance and concentration, preliminary measurements have been made. The linear relationship was established in the range of $0 \rightarrow 60 \mathrm{mg} \mathrm{L}^{-1}$. Thus, the presently chosen 
concentration $60 \mathrm{mg} \mathrm{L}^{-1}$ was the maximum concentration of the established linear concentration versus absorbance range. It was found that this concentration is also close to the solubility limit of AZS in water. A $3 \mathrm{~mL}$ aliquot was collected for performing absorption spectrophotometry, and it was poured back into the reactor after measurement. The first concentration measurement was done in the dark. It was then verified that the herbicide was not adsorbed on the titania film. Finally, the products of photodegradation have been monitored by LC-MS-MS analysis.

\subsection{Apparatus and methods}

Absorption measurements were made with a Cary $1 \mathrm{E}$ spectrophotometer. LC-MS-MS analysis was carried out on a Varian 1200L mass spectrometer equipped with electrospray ionization interface (ESI). The ion trap was connected to a Varian 1200 LC system consisting of two individual pumps, a membrane degasser, an autosampler with temperature control, and a thermostatic column control. The chromatographic separation was performed on a reversed phase Varian Polaris C-18 column $(150 \mathrm{~mm} \times 2.1 \mathrm{~mm}, 5 \mu \mathrm{m}$ particle size $)$ at $30^{\circ} \mathrm{C}$. The concentration of AZS at each degradation stage was calculated by using an external calibration curve from LC-MS-MS measurements of AZS at five different concentrations. Stock solution was prepared by diluting the appropriate amount of the analytical standard with water/methanol (70/30) at concentration $60 \mathrm{ppm}$. In order to determine the degradation products formed during AZS photocatalysis, ESI ionization in both negative- and positiveion modes was investigated. The results indicated that the ESI source at positive-ion mode with collision energy at $30 \mathrm{~V}$ was most appropriate for the analysis of the degradation products.

\section{RESULTS AND DISCUSSION}

The films made by the sol-gel procedure described in the Experimental section consisted of anatase nanocrystals of about $15 \mathrm{~nm}$ average size. Size polydispersity is limited and the active surface area is around $110 \mathrm{~m}^{2} / \mathrm{g}$, as measured by nitrogen adsorption-desorption isotherms according to the BET analysis [21].

\subsection{Photodegradation studies of AZS with pure $\mathrm{TiO}_{2}$ films}

It has been proposed that titanium dioxide mediated photodegradation involves the generation of electron-hole pairs [2], which migrate to the photocatalyst surface forming surface bound hydroxyl and superoxide radicals according to following reactions:

$$
\begin{gathered}
\mathrm{TiO}_{2}+h v \longrightarrow \mathrm{e}_{\mathrm{cb}}^{-}+\mathrm{h}_{\mathrm{vb}}^{+}, \\
\mathrm{O}_{2}+\mathrm{e}_{\mathrm{cb}}^{-} \longrightarrow \mathrm{O}_{2}^{-\bullet}, \\
\mathrm{H}_{2} \mathrm{O}++\mathrm{h}_{\mathrm{vb}}^{+} \longrightarrow \cdot \mathrm{OH}+\mathrm{H}^{+} .
\end{gathered}
$$

It is commonly known that the hydroxyl and superoxide radicals are the primary oxidizing species in the photo-

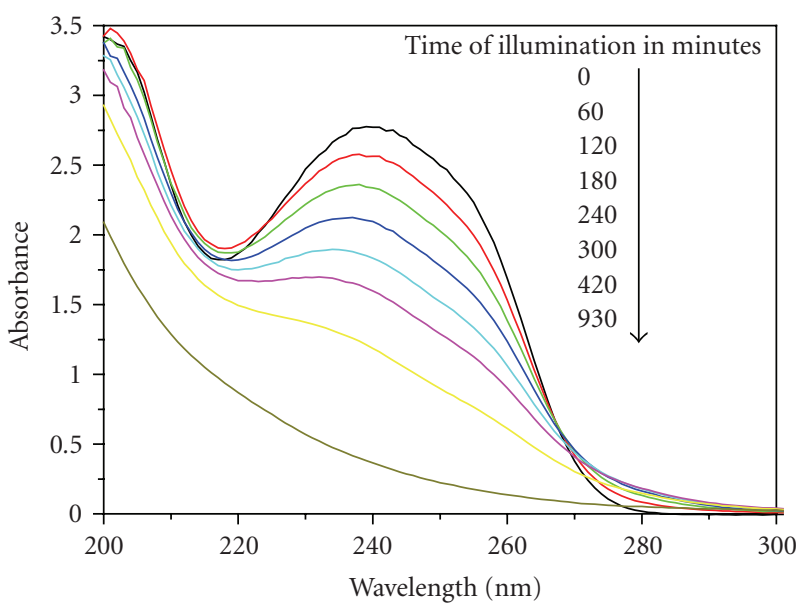

FIGURE 2: Absorption spectrum of AZS in water and variation with time of UV illumination in the presence of $\mathrm{TiO}_{2}$ nanocrystalline films.

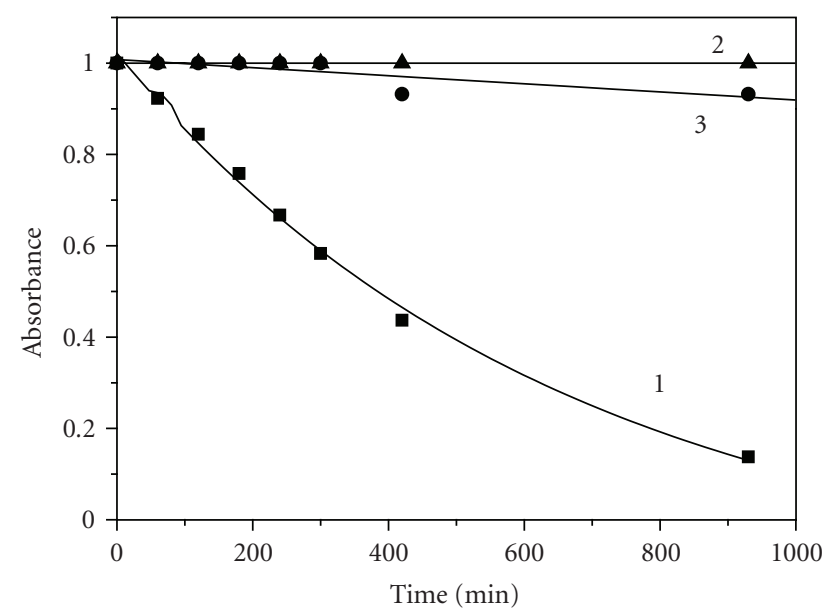

FIgure 3: Photodegradation curves of AZS with black light illumination: in the presence of $\mathrm{TiO}_{2}$ films (1); in the absence of photocatalyst (2); and in the absence of oxygen (3).

catalytic process. These oxidative reactions result in the photodegradation of AZS. The efficiency of this process depends on oxygen concentration. The absorption spectra of the AZS solution at various stages of photodegradation are presented in Figure 2, where it is obvious that the concentration of intact AZS decreased during illumination in the presence of titania. The characteristic peak at $240 \mathrm{~nm}$ completely disappears after 15 hours of illumination, using low-power black light source. Practically, no photolysis of AZS has been observed at the present illumination level, as seen by curve number 2 of Figure 3. The presence of oxygen during photocatalytic experiments is absolutely necessary and this is proved by the data of curve number 3 in Figure 3. Absence of oxygen leads to negligible photodegradation. Photodegradation followed Langmuir-Hinshelwood kinetics:

$$
\ln \left(A_{0} / A\right)=k_{\text {app }} t
$$


The corresponding first-order rate constant was $0.0020 \mathrm{~min}^{-1}$. By taking into account the fact that no AZS was adsorbed on the titania films, as already said, it is obvious that photodegradation is carried out in the liquid phase and it is also obvious that $\mathrm{O}_{2}{ }^{-\bullet}$ species, which are only formed in the presence of oxygen, play a major role. Furthermore, the fact that photodegradation is carried out in the liquid phase explains why it is relatively slow. As a matter of fact, it is known that photodegradation rates are higher when the target substance is adsorbed on the photocatalyst.

\subsection{Photodegradation of AZS in presence of noble metals deposited on $\mathrm{TiO}_{2}$ films}

Silver or platinum metal ions were deposited on the $\mathrm{TiO}_{2}$ surface by submerging titania for several minutes in aqueous solutions of metal salts. Metal cations could be adsorbed in $\mathrm{TiO}_{2}$ films at substantial quantities because of the relatively high specific surface area of the films. The platinum complex is in the form of divalent tetrachloride ion. By accepting two photo-generated electrons, it is converted into zero valence metal according to the following reaction:

$$
\mathrm{PtCl}_{4}{ }^{2-}+2 \mathrm{e}^{-} \longrightarrow \mathrm{Pt}^{0}+4 \mathrm{Cl}^{-} .
$$

However, XPS measurements for UV illuminated samples gave peaks with binding energies of 72.85 and $76.13 \mathrm{eV}$, consistent with published values [22] for $\mathrm{Pt}^{(\mathrm{II})}$. In addition to UV exposure, thermal heating $\left(500^{\circ} \mathrm{C}\right)$ of the metaldeposited films gave a variation of the binding energies of platinum, which were then located at 70.5 and $73.86 \mathrm{eV}$, consistent with $\mathrm{Pt}^{(0)}$ [22]. It is obvious that weak UV light intensity from black light irradiation was not enough for the complete transformation of tetrachloroplatinate ion into zero valence platinum. However, it is possible that $\mathrm{Pt}^{(\mathrm{II})}$ is finally transformed into $\mathrm{Pt}^{(0)}$, due to the prolonged $\mathrm{UV}$ illumination during photodegradation. In the case of silver ions, the results were more predictable as only one electron is enough to reduce silver ions and create zero valence noble metal on the surface of $\mathrm{TiO}_{2}$, according to the following reaction:

$$
\mathrm{Ag}^{+1}+\mathrm{e}^{-} \longrightarrow \mathrm{Ag}^{0} .
$$

This electron is easy to be generated, either by UV illumination under black light irradiation or by thermal heating of the films [23]. XPS measurements gave similar results for both procedures of silver reduction. The photodegradation of AZS herbicide in the presence of platinum modified titania films is presented in Figure 4. The films subjected to both UV and thermal treatment gave better photocatalytic efficiencies as compared with the films, which were only UV treated. Furthermore, the original salt concentration, which obviously affects the quantity of deposited metal, affected photodegradation efficiency. When the platinum salt concentration was $5 \times 10^{-4} \mathrm{~mol} \mathrm{~L}^{-1}$, we obtained the highest photocatalytic efficiency. At higher metal load, efficiency dropped, possibly due to screening effects. The photocatalytic degradation of AZS in presence of silver loaded $\mathrm{TiO}_{2}$ is presented in

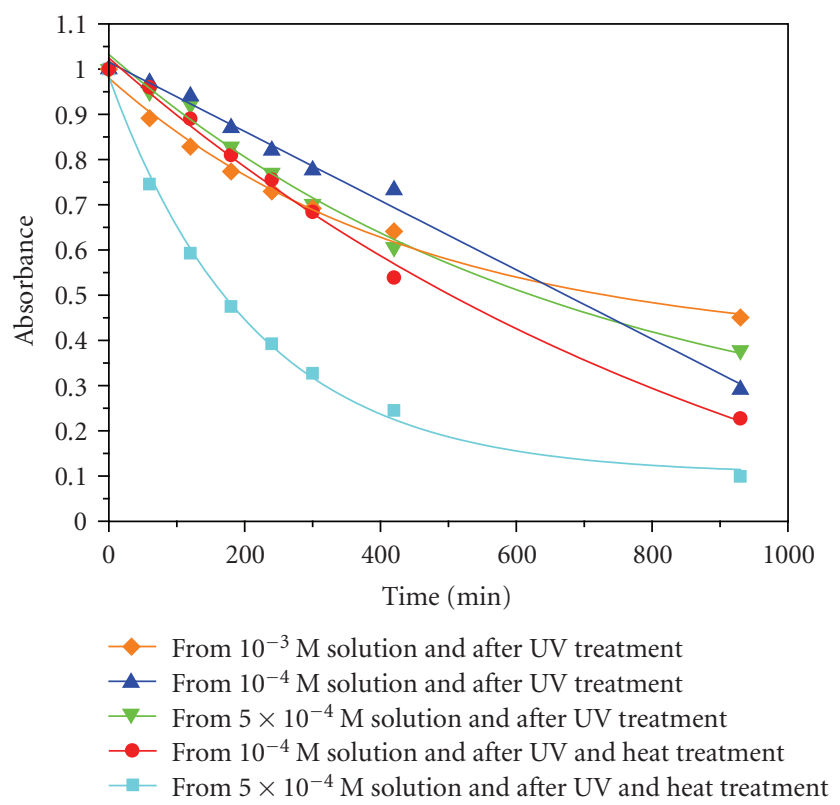

FIgure 4: Photodegradation curves of AZS with black light illumination in presence of $\mathrm{Pt}$ modified $\mathrm{TiO}_{2}$ films at various platinum concentrations and treatments of the films.

Figure 5(a). As in the case of platinum, metal load affected photocatalysis, $10^{-2} \mathrm{~mol} \mathrm{~L}^{-1}$ silver salt concentration giving the best results. Silver deposited on $\mathrm{TiO}_{2}$ films gave the plasmon resonance absorption [23] spectra of Figure 5(b). Absorbance values verified that there is a direct relation between metal load and salt concentration in the aqueous solution. Comparative studies of AZS photodegradation with pure or metal-loaded $\mathrm{TiO}_{2}$ showed that the presence of platinum is effective for the destruction of the herbicide contrary to silver, which gave similar results as pure $\mathrm{TiO}_{2}$ films (see Figure 6). The role of platinum in photocatalysis is not fully understood. The degree of enhancement of the activity of $\mathrm{TiO}_{2}$ by platinisation seems to depend highly on the substance to be photodegraded [24], the characteristics and the amount of deposited Pt [25], and the structural and morphological properties of original $\mathrm{TiO}_{2}$ [26]. In general, it is accepted, as already said, that in platinized $\mathrm{TiO}_{2}$, a better separation of charge carriers is observed.

\subsection{AZS photodegradation intermediates}

Intermediate products of AZS photodegradation were studied by LC-MS-MS. Two major ions were detected in all photodegradation stages, one with m/z: 199 and the other with $\mathrm{m} / \mathrm{z}: 244$. These two fragments exactly correspond to the amino-dimethoxypyrimidine and 1-methyl-4-(2-methyl$2 \mathrm{H}$-tetrazole-5-yl)-1H-pyrazole-5-sulfonamide moieties, respectively, which AZS consists of. Ion 244 yielded a major further fragment ion at $\mathrm{m} / \mathrm{z}: 83.3$, which could correspond to the sulfonamide $\mathrm{SO}_{2} \mathrm{NH}_{2^{-}}$group. The amino-dimethoxypyrimidine-containing ion yielded a major fragment ion at m/z: 74.5 , which could correspond to the break down of the carbon link between the two nitrogen 


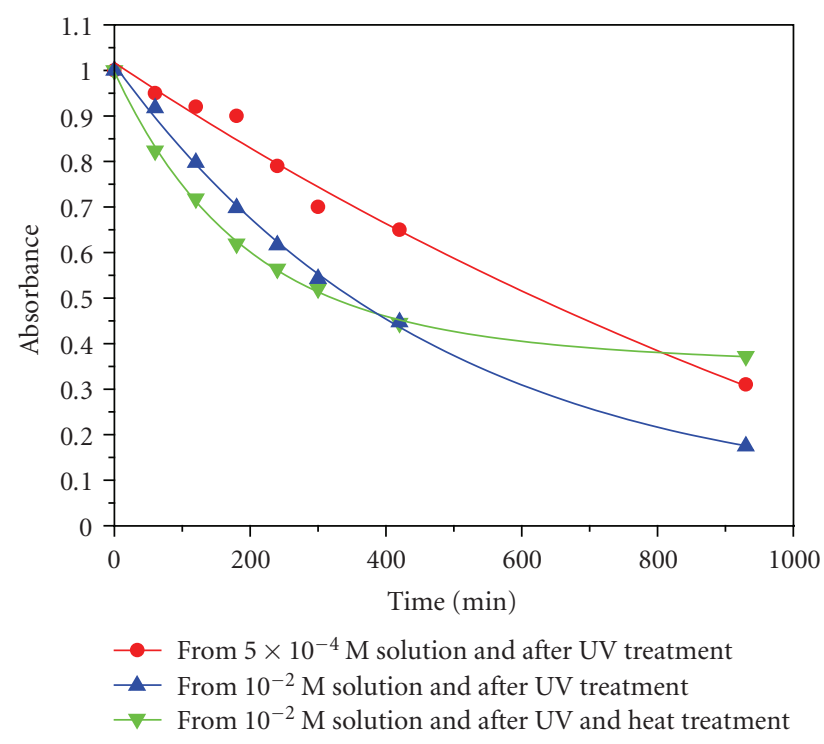

(a)

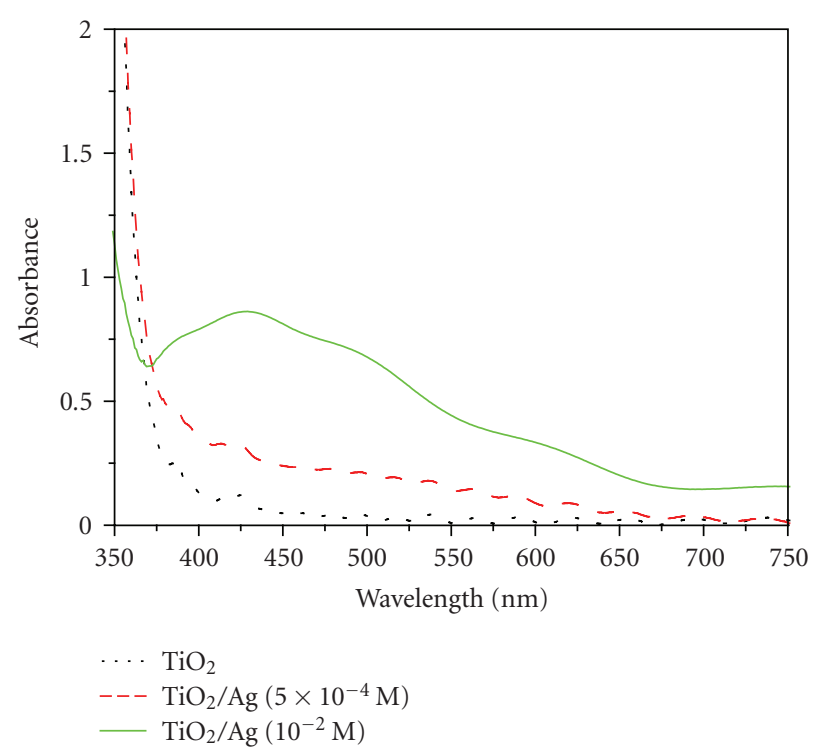

(b)

FIGURE 5: (a) Photodegradation curves of AZS with black light illumination in the presence of $\mathrm{Ag}$ modified $\mathrm{TiO}_{2}$ films at various silver concentrations and treatments of the films: (a) - $\bullet$ - from $5 \times 10^{-4} \mathrm{M}$ solution and after UV treatment; (b) $-\boldsymbol{\Delta}$ - from $10^{-2} \mathrm{M}$ solution and after UV treatment; (c) $-\nabla$ - from $10^{-2} \mathrm{M}$ solution and after UV and heat treatment.

atoms leading to the formation of methylaminocarboxylic acid $\mathrm{CH}_{3} \mathrm{NHCOOH}$. These data are preliminary and further studies on the detailed reaction pathway are being conducted in our laboratories.

\section{4. pH effect on the photodegradation of AZS}

The photodegradation of AZS was also studied at various $\mathrm{pH}$ values. The results are presented in Figure 7. $\mathrm{pH}$ values

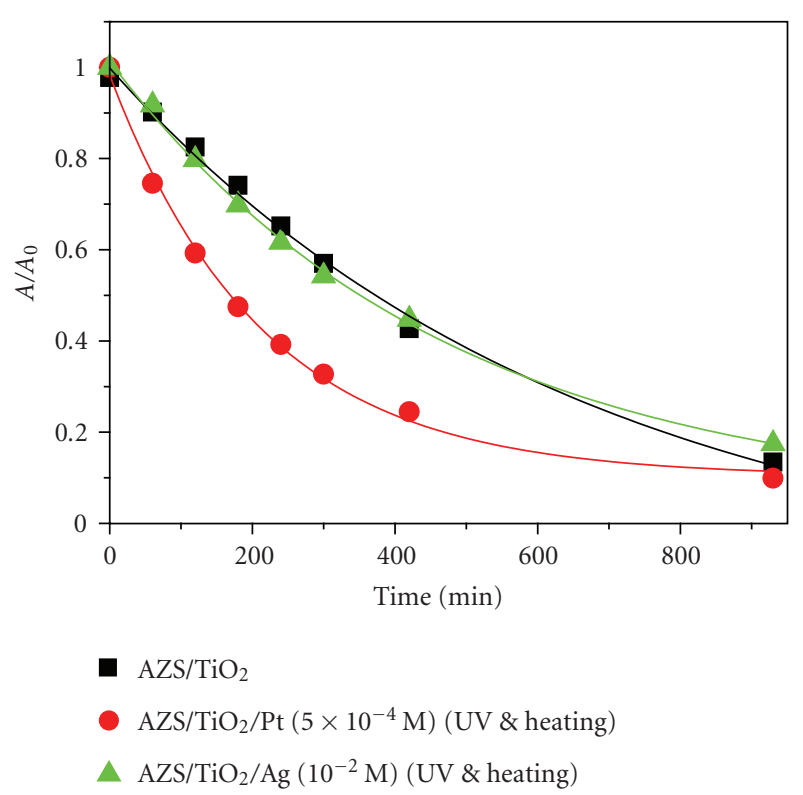

FIGURE 6: Comparative photodegradation curves of AZS with black light illumination in the presence of pure and modified $\mathrm{TiO}_{2}$ films.

were modified by adding either $\mathrm{H}_{2} \mathrm{SO}_{4}$ or $\mathrm{NaOH}$, both at a concentration of $0.1 \mathrm{~mol} \mathrm{~L}^{-1}$. The fastest photodegradation was obtained at natural $\mathrm{pH}$ (4.7), that is, in a pure solution of AZS in water. Photodegradation rates in basic $\mathrm{pH}$ were low and even lower in acidic $\mathrm{pH}$. This behavior could be explained by the fact that AZS possesses chargeable chemical groups. It is highly probable that at low $\mathrm{pH}$ values, AZS is positively charged, and at high $\mathrm{pH}$ values, it is negatively charged. However, as it is well known that the surface of titania is also charged with the same charge at the same $\mathrm{pH}$ [27]. Therefore, at low or high $\mathrm{pH}$, there is a repulsion that separates the catalyst surface from the target molecule and makes it more difficult for the reactive radical species, which are generated on the surface of the catalyst, to reach the target molecules; hence the lower photodegradation rates in these cases. The right axis scale of all graphs of Figure 7 represents the change of $\mathrm{pH}$ in the solution during illumination. In strongly alkaline and acidic solutions, $\mathrm{pH}$ decreased during photodegradation, but in the case of natural solutions, a $\mathrm{pH}$ increase was observed. The interpretation of the $\mathrm{pH}$ effect on the photocatalytic process is a rather difficult task because of the multiple roles that various factors could play, such as electrostatic interactions with the semiconductor surface, chemical structure of the original substance and of its fragments, and formation of active radicals.

\section{CONCLUSIONS}

The herbicide azimsulfuron can be effectively photodegraded by employing pure or noble metal-modified titania nanocrystalline films as photocatalysts with black light tubes as low-intensity UV illumination source. The catalyst was deposited by the sol-gel method on glass rings; it could be 


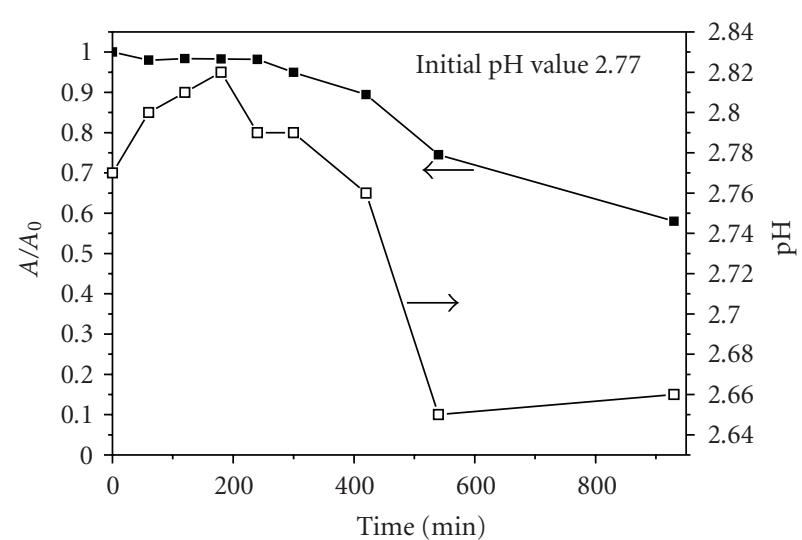

(a)

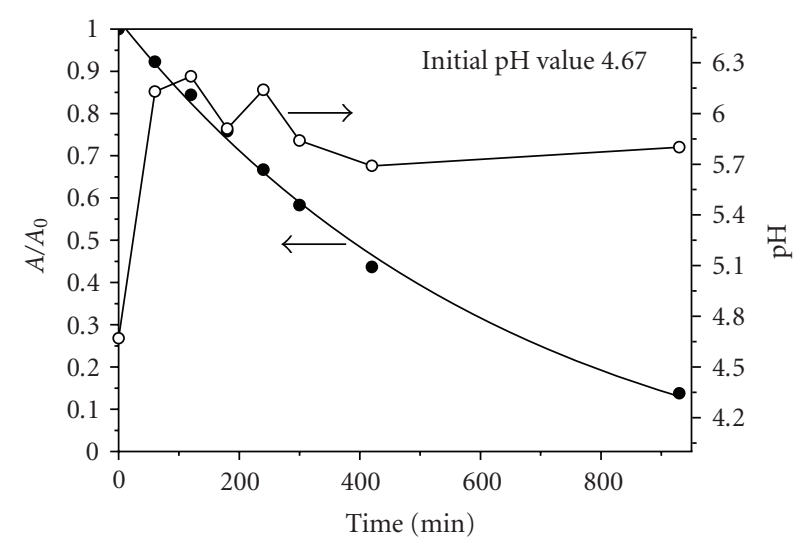

(b)

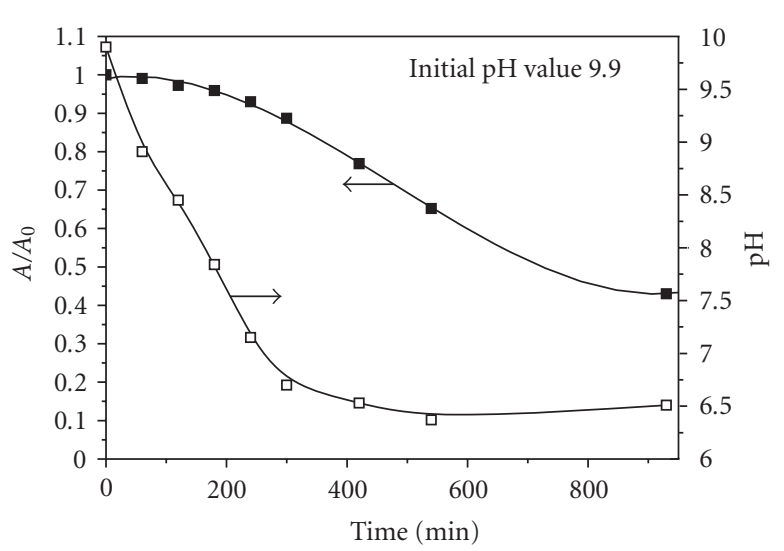

(c)

FIGURE 7: Effect of $\mathrm{pH}$ variation in the photodegradation rates with pure nanocrystalline titania films (a) in acidic $\mathrm{pH}$; (b) in natural $\mathrm{pH}$ of AZS in water; (c) in alkaline $\mathrm{pH}$ value.

thus easily recuperated and repeatedly used in subsequent photodegradation procedures. The best photocatalytic rates were achieved in the case of platinum modified nanocrystalline $\mathrm{TiO}_{2}$ films. The $\mathrm{pH}$ of AZS aqueous solution affected photodegradation rates. The fastest rate was obtained in the case of natural $\mathrm{pH}$ of the solution.

\section{ACKNOWLEDGMENT}

The authors acknowledge financial support from the Greek General Secretariat of Research and Technology through the E\&T bilateral GR-USA cooperation program, 05NON-EU521.

\section{REFERENCES}

[1] D. Bahnemann, "Photocatalytic detoxification of polluted waters," in The Handbook of Environmental Chemistry. Vol. II. Part L, O. Hutzinger, Ed., pp. 285-351, Springer, Berlin, Germany, 1999.

[2] M. R. Hoffmann, S. T. Martin, W. Choi, and D. W. Bahnemann, "Environmental applications of semiconductor photocatalysis," Chemical Reviews, vol. 95, no. 1, pp. 69-96, 1995.

[3] E. Evgenidou, I. Konstantinou, K. Fytianos, I. Poulios, and T. Albanis, "Photocatalytic oxidation of methyl parathion over $\mathrm{TiO}_{2}$ and $\mathrm{ZnO}$ suspensions," Catalysis Today, vol. 124, no. 3-4, pp. 156-162, 2007.

[4] O. Zahraa, H. Y. Chen, and M. Bouchy, "Photocatalytic degradation of 1,2-dichloroethane on supported $\mathrm{TiO}_{2}$," Journal of Advanced Oxidation Technologies, vol. 4, pp. 1169-1176, 1999.

[5] S. Malato, J. Blanco, J. Cáceres, A. R. Fernández-Alba, A. Agüera, and A. Rodríguez, "Photocatalytic treatment of watersoluble pesticides by photo-Fenton and $\mathrm{TiO}_{2}$ using solar energy," Catalysis Today, vol. 76, no. 2-4, pp. 209-220, 2002.

[6] Z. Zou, J. Ye, K. Sayama, and H. Arakawa, "Direct splitting of water under visible light irradiation with an oxide semiconductor photocatalyst," Nature, vol. 414, no. 6864, pp. 625-627, 2001.

[7] L. Sun and J. R. Bolton, "Determination of the quantum yield for the photochemical generation of hydroxyl radicals in $\mathrm{TiO}_{2}$ suspensions," Journal of Physical Chemistry, vol. 100, no. 10, pp. 4127-4134, 1996.

[8] D. Ollis and H. Al-Ekabi, Eds., Photocatalytic Purification and Treatment of Water and Air, Elsevier Science, Amsterdam, The Netherlands, 1993.

[9] R. Memming, Semiconductor Electrochemistry, Wiley-VCH, Weinheim, Germany, 2001.

[10] S. Sakthivel, M. V. Shankar, M. Palanichamy, B. Arabindoo, D. W. Bahnemann, and V. Murugesan, "Enhancement of photocatalytic activity by metal deposition: characterisation and photonic efficiency of $\mathrm{Pt}, \mathrm{Au}$ and $\mathrm{Pd}$ deposited on $\mathrm{TiO}_{2}$ catalyst," Water Research, vol. 38, no. 13, pp. 3001-3008, 2004.

[11] N. Serpone and E. Pelizzetti, Eds., PhotocatalysisFumdamentals and Applications, Wiley-Interscience, New York, NY, USA, 1989.

[12] D. Hufschmidt, D. Bahnemann, J. J. Testa, C. A. Emilio, and M. I. Litter, "Enhancement of the photocatalytic activity of various $\mathrm{TiO}_{2}$ materials by platinisation," Journal of Photochemistry and Photobiology A, vol. 148, no. 1-3, pp. 223-231, 2002.

[13] I. K. Konstantinou, V. A. Sakkas, and T. A. Albanis, "Photocatalytic degradation of propachlor in aqueous $\mathrm{TiO}_{2}$ suspensions. Determination of the reaction pathway and identification of intermediate products by various analytical methods," Water Research, vol. 36, no. 11, pp. 2733-2742, 2002.

[14] V. A. Sakkas, I. M. Arabatzis, I. K. Konstantinou, A. D. Dimou, T. A. Albanis, and P. Falaras, "Metolachlor photocatalytic degradation using $\mathrm{TiO}_{2}$ photocatalysts," Applied Catalysis B, vol. 49, no. 3, pp. 195-205, 2004. 
[15] M. V. Pinna, M. Zema, C. Gessa, and A. Pusino, "Structural elucidation of phototransformation products of azimsulfuron in water," Journal of Agricultural and Food Chemistry, vol. 55, no. 16, pp. 6659-6663, 2007.

[16] A. Pusino, M. V. Pinna, and C. Gessa, "Azimsulfuron sorptiondesorption on soil," Journal of Agricultural and Food Chemistry, vol. 52, no. 11, pp. 3462-3466, 2004.

[17] V. Maurino, C. Minero, E. Pelizzetti, and M. Vincenti, "Photocatalytic transformation of sulfonylurea herbicides over irradiated titanium dioxide particles," Colloids and Surfaces A, vol. 151, no. 1-2, pp. 329-338, 1999.

[18] S. Rafqah, P. Wong-Wah-Chung, A. Aamili, and M. Sarakha, "Degradation of metsulfuron methyl by heterogeneous photocatalysis on $\mathrm{TiO}_{2}$ in aqueous suspensions: kinetic and analytical studies," Journal of Molecular Catalysis A, vol. 237, no. 1-2, pp. 50-59, 2005.

[19] N. Strataki, V. Bekiari, D. I. Kondarides, and P. Lianos, "Hydrogen production by photocatalytic alcohol reforming employing highly efficient nanocrystalline titania films," Applied Catalysis B, vol. 77, no. 1-2, pp. 184-189, 2007.

[20] P. Bouras, E. Stathatos, and P. Lianos, "Pure versus metalion-doped nanocrystalline titania for photocatalysis," Applied Catalysis B, vol. 73, no. 1-2, pp. 51-59, 2007.

[21] E. Stathatos, P. Lianos, and C. Tsakiroglou, "Highly efficient nanocrystalline titania films made from organic/inorganic nanocomposite gels," Microporous and Mesoporous Materials, vol. 75, no. 3, pp. 255-260, 2004.

[22] B. Ohtani, K. Iwai, S. Nishimoto, and S. Sato, "Role of platinum deposits on titanium(IV) oxide particles: structural and kinetic analyses of photocatalytic reaction in aqueous alcohol and amino acid solutions," Journal of Physical Chemistry B, vol. 101, no. 17, pp. 3349-3359, 1997.

[23] E. Stathatos, P. Lianos, P. Falaras, and A. Siokou, "Photocatalytically deposited silver nanoparticles on mesoporous $\mathrm{TiO}_{2}$ films," Langmuir, vol. 16, no. 5, pp. 2398-2400, 2000.

[24] F. Denny, J. Scott, K. Chiang, W. Y. Teoh, and R. Amal, "Insight towards the role of platinum in the photocatalytic mineralisation of organic compounds," Journal of Molecular Catalysis A, vol. 263, no. 1-2, pp. 93-102, 2007.

[25] J. Lee and W. Choi, "Photocatalytic reactivity of surface platinized $\mathrm{TiO}_{2}$ : substrate specificity and the effect of $\mathrm{Pt}$ oxidation state," Journal of Physical Chemistry B, vol. 109, no. 15, pp. 7399-7406, 2005.

[26] M. C. Hidalgo, M. Maicu, J. A. Navío, and G. Colón, "Photocatalytic properties of surface modified platinised $\mathrm{TiO}_{2}$ : effects of particle size and structural composition," Catalysis Today, vol. 129, no. 1-2, pp. 43-49, 2007.

[27] M. Carrier, N. Perol, J.-M. Herrmann, et al., "Kinetics and reactional pathway of Imazapyr photocatalytic degradation Influence of $\mathrm{pH}$ and metallic ions," Applied Catalysis B, vol. 65, no. 1-2, pp. 11-20, 2006. 


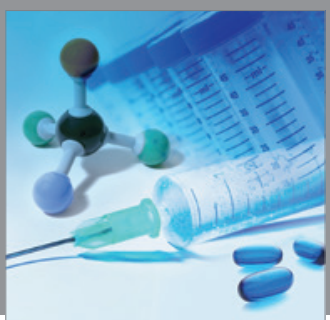

International Journal of

Medicinal Chemistry

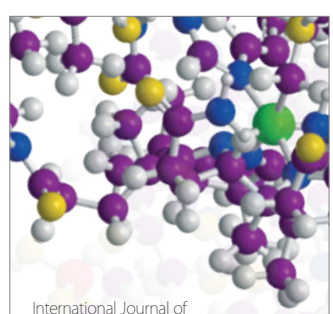

Carbohydrate Chemistry

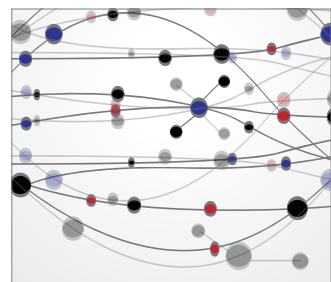

The Scientific World Journal
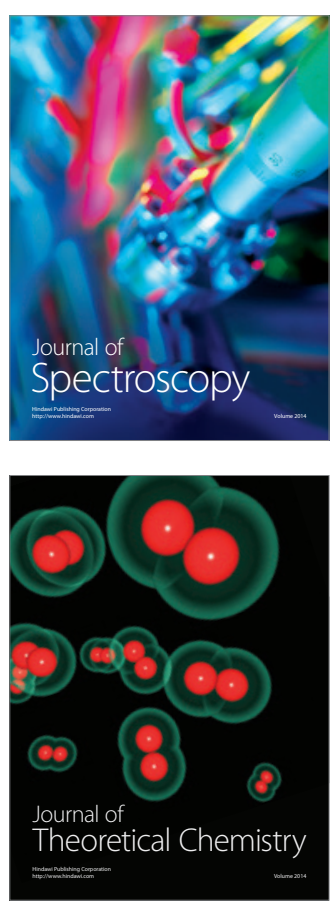
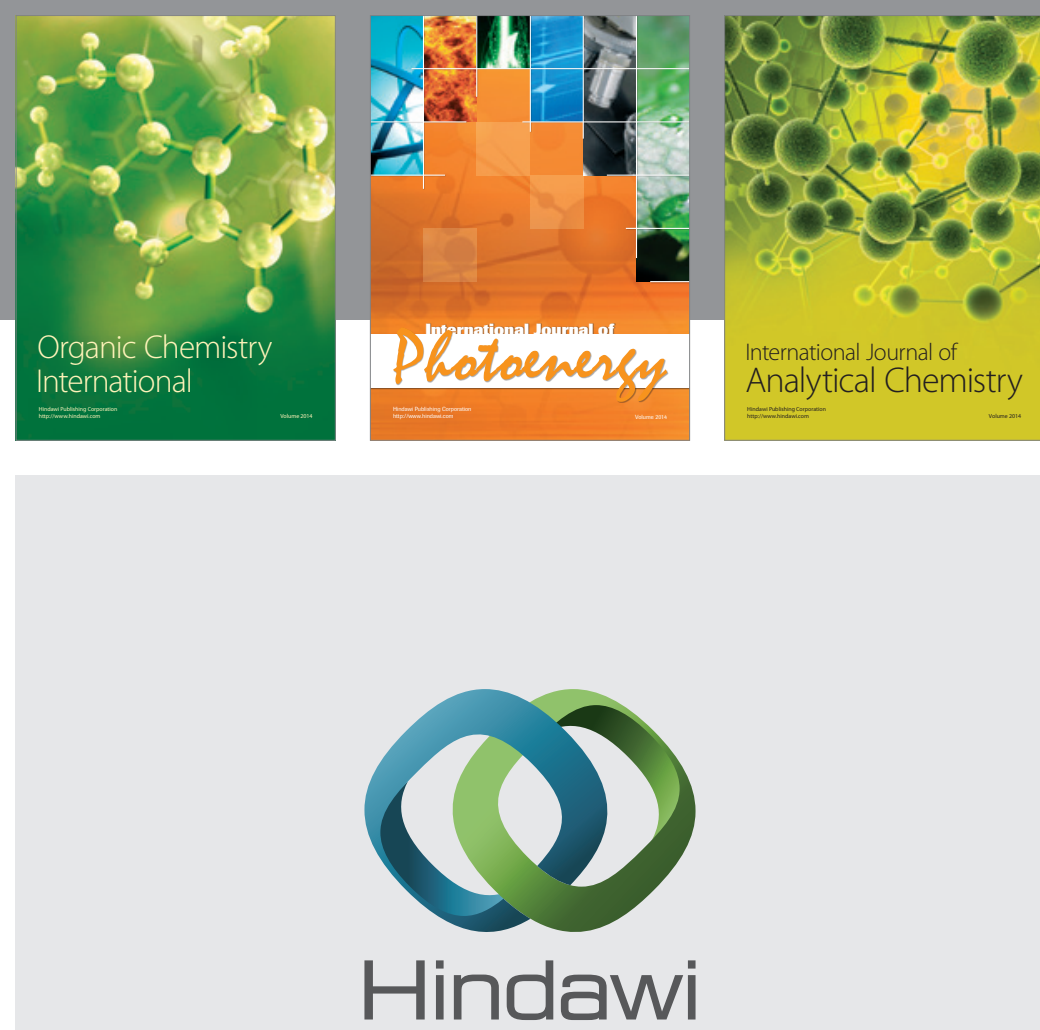

Submit your manuscripts at

http://www.hindawi.com
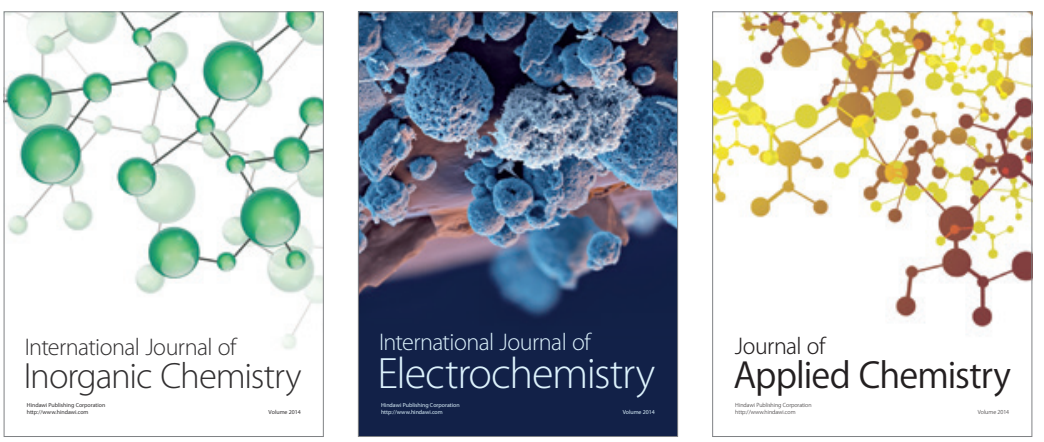

Journal of

Applied Chemistry
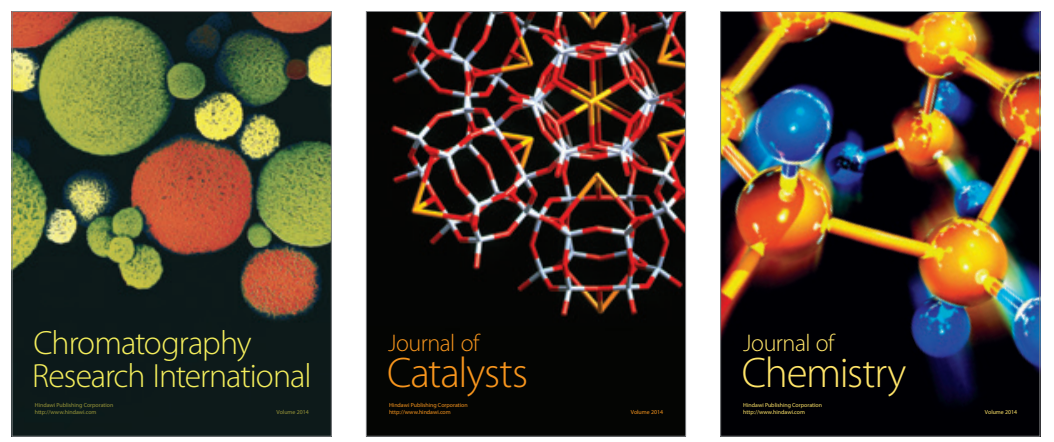
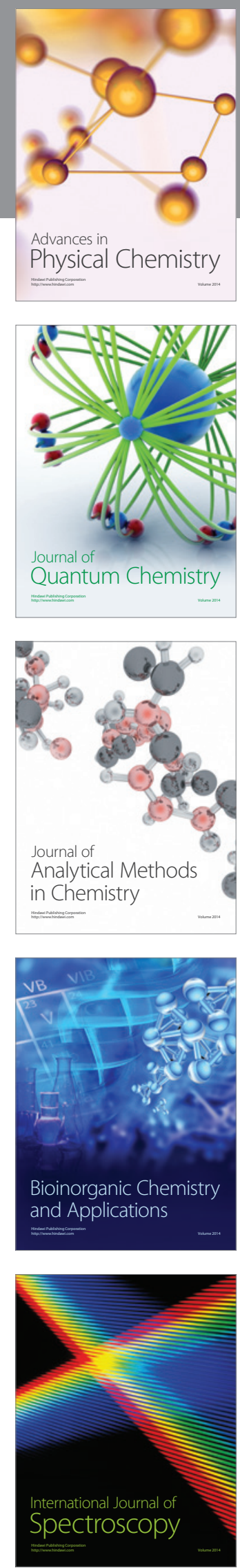